\title{
IDENTIFIKASI ALAT BANTU PENANGKAPAN IKAN PADA BAGAN APUNG DI PERAIRAN KRUENG RAYA
}

\section{IDENTIFICATION OF FISHING TOOLS IN BAGAN APUNG AT THE KRUENG RAYA AREA}

\author{
Edy Miswar1, Fachrurozi Amir1, M.A. Chaliluddin1, Junaidi M. Affan1
}

\author{
1 Program Studi Pemanfaatan Sumberdaya Perikanan, Fakultas Kelautan dan Perikanan, Universitas \\ Syiah Kuala, Banda Aceh, Aceh-Indonesia \\ * Korespondensi :email : edymiswar@unsyiah.ac.id, fachruroziamir@gmail.com
}

\begin{abstract}
ABSTRAK
Perikanan bagan apung di Perairan Krueng Raya merupakan salah satu sektor perikanan utama yang menjadi sumber mata pencaharian masyarakat pesisir. Pengoperasian alat tangkap selalu didukung dengan adanya alat bantu penangkapan yang dapat membantu proses pengoperasian, begitu juga dengan bagan apung yang ada di Perairan Krueng Raya. Alat bantu utama pada bagan di Perairan Krueng Raya adalah lampu, genset dan roller. Kurangnya data dan informasi mengenai karakteristik alat bantu penangkapan dinilai dapat menjadi kendala dalam melakukan pengembangan perikanan bagan apung yang lebih maju. Penelitian ini bertujuan untuk mengidentifikasi alat bantu yang digunakan pada bagan apung di Perairan Krueng Raya. Pengumpulan data dilakukan dengan wawancara dan pengamatan langsung dilapangan. Hasil analisis deskriptif menunjukkan alat bantu penangkapan ikan pada bagan apung di Perairan Krueng Raya menggunakan lampu neon dan mercury, kapasitas genset sebesar 5000 watt dan roller terbuat dari kayu bayur (Pterospermum javanicum) dan kayu kelapa (Cocos sp.). Pemanfaatan alat bantu pada bagan apung di Perairan Krueng Raya saat ini masih dapat dilakukan pembaharuan.
\end{abstract}

Kata kunci: Krueng Raya, Bagan Apung

\begin{abstract}
Lift-nets is one of the important fisheries sectors that become the source of coastal comunity livelihood in Krueng Raya, Aceh Besar. The operation of the fishing gear is always supported by the fishing tools that can assist the operation process, as well as the lift-nets that exist in the Krueng Raya area. The main fishing tools on the lift-nets in Krueng Raya are lights, generator and roller. The lack of data and information on the characteristics of fishing equipment becomes an obstacle to improve the development of lift-nets. This study aims to identify fishing equipment used in lift-nets at Krueng Raya. The data were collected by interviewed and directed field observation. Descriptive analysis showed the fishing equipment used in lift-nets in Krueng Raya used neon and mercury lamps, the generator capacity is 15000 watts and roller made of bayur wood (Pterospermum javanicum). The updates of the fishing equipment used in lift-nets at Krueng Rayacan still be made.
\end{abstract}

Kata kunci: Krueng Raya, Lift Net

\section{PENDAHULUAN}

Perairan Aceh memiliki peran yang sangat penting dalam pengembangan sektor kelautan dan perikanan baik di Aceh maupun di Indonesia. Potensi lestari di laut yang dimiliki Aceh diperkirakan mencapai 272,7 ribu ton/tahun dan masih belum dimanfaatkan sepenuhnya (BPS Aceh, 2015). Upaya memanfaatkan kekayaan alam yang ada di laut secara optimal dan lestari adalah tuntutan bagi bangsa dalam hal memakmurkan rakyat, khususnya bagi kemakmuran nelayan, pemenuhan kebutuhan gizi masyarakat, memperluas lapangan kerja serta peningkatan pasar ekspor untuk menghasilkan devisa negara. Beberapa upaya telah dilakukan dalam pemanfaatan sumberdaya perikanan di Aceh, salah satunya ialah metode penangkapan ikan dengan menggunakan bagan apung.

Bagan merupakan alat penangkap ikan yang bersifat pasif, yakni menunggu gerombolan ikan mendekati alat tangkap dengan bantuan 
cahaya lampu sebagai attractor (Sudirman dan Mallawa, 2012). Perairan Aceh Besar khususnya Krueng Raya merupakan kawasan pesisir yang terdapat banyak pengoperasian bagan apung oleh nelayannya. Penggunaan bagan apung sebagai alat penangkap ikan di Perairan Krueng Raya sudah ada sejak sebelum tahun 1977 dengan beberapa alat tangkap lainnya seperti pancing ulur, jaring insang (gillnet), dan perangkap. Penggunaan bagan apung pada saat itu masih sangat sederhana. Hingga saat ini alat tangkap bagan apung yang ada di Perairan Krueng Raya masih menjadi alat tangkap yang dominan digunakan jika dibandingkan dengan alat tangkap lainnya.

Pengoperasian alat tangkap selalu didukung dengan adanya alat bantu penangkapan yang memadai. Alat bantu penangkapan utama yang digunakan pada bagan apung adalah cahaya lampu, genset dan roller. Fungsi cahaya sebagai pemikat ikan (ikan yang bersifat fototaksis positif) agar berkumpul di sekitaran bagan, sehingga alat tangkap dapat dioperasikan (Puspito, 2012). Genset pada bagan apung digunakan sebagai sumber tenaga listik untuk menghidupkan lampu dan keperluan listrik lainnya, sedangkan roller dibutuhkan dalam penarikan jaring pada saat hauling.

Penelitian mengenai bagan apung telah banyak dilakukan oleh peneliti sebelumnya. Penelitian seperti faktor produksi perikanan bagan, pengaruh lamanya perendaman dan penyinaran lampu dan beberapa penelitian lainnya sudah pernah dilakukan, namun sejauh pengamatan penulisbelum ada penelitian mengenai identifikasi alat bantu penangkapan pada bagan apung di Perairan Krueng Raya. Maka dari itu perlu dilakukan penelitian mengenai identifikasi alat bantu penangkapan guna memberikan gambaran mengenai karakteristik alat bantu penangkapan yang digunakan pada bagan apung di Perairan Krueng Raya.

\section{BAHAN DAN METODE Waktu dan Tempat}

Penelitian dilaksanakan selama 1 bulan terhitung mulai tanggal 16 Januari sampai 16 Februari 2017 di Perairan Krueng Raya. Peta lokasi penelitian dapat dilihat pada Gambar 1

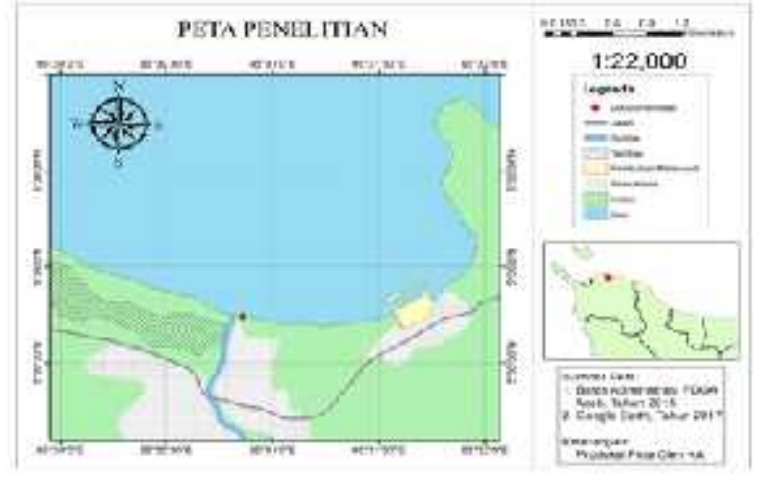

Gambar 1. Peta lokasi penelitian

\section{Alat dan bahan}

Alat dan bahan yang digunakan pada penelitian ini dapat dilihat pada Tabel 1 berikut: Tabel 1. Alat dan bahan serta kegunaannya

\begin{tabular}{|c|c|}
\hline Alat dan Bahan & Kegunaan \\
\hline Kamera & $\begin{array}{l}\text { Dokumentasi dan pengamatan } \\
\text { tata letak lampu }\end{array}$ \\
\hline Meteran & $\begin{array}{l}\text { Mengukur panjang dan } \\
\text { diameter roller }\end{array}$ \\
\hline Kuesioner & $\begin{array}{l}\text { Memperoleh informasi dari } \\
\text { responden }\end{array}$ \\
\hline
\end{tabular}

\section{Pengambilan data}

Metode yang digunakan dalam penelitian ini adalah metode survey. Data yang dikumpulkan berupa data primer dan data sekunder. Data primer yang dikumpulkan meliputi jenis dan fungsi alat bantu penangkapan ikan yang ada di bagan apung serta teknis penggunaan alat bantu penangkapan. Data sekunder berupa data pembanding hasil penelitian diperoleh melalui buku, jurnal, skripsi, dan tesis.

\section{Analisis data}

Data pada penelitian ini dianalisis dengan menggunakan metode deskriptif untuk mengetahui jenis dan teknis penggunaan dari alat bantu penangkapan ikan pada bagan apung di Perairan Krueng Raya.

\section{HASIL DAN PEMBAHASAN \\ Perikanan bagan apung di Krueng Raya}

Perikanan bagan apung di Perairan Krueng Raya mulai mengalami kemajuan sejak tahun 1900-an, yakni dengan mulai menggunakan lampu dengan bantuan genset serta bangunan rumah bagan apung dan alat tangkap yang semakin membaik. Peristiwa tsunamipada tahun 2004 menjadikan aktivitas 
perikanan bagan apung di Perairan Krueng Raya terhenti hingga beberapa bulan. Hampir seluruh bagan apung hancur ketika terjadi tsunami dan hanya beberapa yang masih utuh, namun karena kondisi saat itu belum kondusif, bagan apung yang masih ada kemudian akhirnya rusak parah dan tidak dapat digunakan kembali. Nelayan Krueng Raya juga mendapatkan bantuan beberapa unit bagan apung dari DKP Aceh, namun unit bagan apung yang diberikan tidak begitu baik dan dapat bertahan lama, sehingga sebagian besar nelayan membuat bagan apung dengan pendanaan sendiri.

Jumlah bagan apung yang ada di Perairan Krueng Raya hingga saat ini berjumlah 30 unit dan memiliki 2 jenis ukuran, yakni bagan apung dengan ukuran jaring $25 \times 25 \mathrm{~m}$ berjumlah 3 unit serta sisanya bagan apung yang memiliki ukuran jaring $18 \times 18 \mathrm{~m}$. Jumlah ABK pada tiap bagan apung di Perairan Krueng Raya sebanyak 6 hingga 8 orang termasuk pawang. Lokasi fishing ground tidak terlalu jauh dari TPI (Tempat Pendaratan Ikan) yakni sekitar 3-5mil dari pantai dan tidak ada sistem pembagian lokasi penangkapan dengan nelayan lainnya. Penentuan lokasi fishing ground didasarkan pada pengalaman pawang.

\section{Operasi alat tangkap bagan apung di Perairan Krueng Raya}

Nelayan umumnya pergi menuju ke fishing ground secara bersamaan dengan pemilik bagan apung lainnya, yakni dengan menggunakan perahu pengantar pada pukul 16.30 atau 17.00 WIB. Fishing ground umumnya ditentukan berdasarkan pengalaman nelayan.Waktu tempuh dari fishing base menuju fishing ground dengan menggunakan perahu pengantar memerlukan waktu sekitar 10 sampai 15 menit. Nelayan biasanya melakukan persiapan operasi setelah sampai di bagan utama, seperti membersihkan bagian atas dan rumah bagan, menjurai jaring yang rusak, menguras air pada perahu, mengisi bahan bakar pada genset, membersihkan kamar dapur, memasak nasi, dan mengganti lampu jika sudah ada yang tidak layak pakai. Sekitar pukul 18.30 WIB genset mulai dihidupkan dan lampu mulai dinyalakan. Nelayan kemudian menungguikan berkumpul disekitar cahaya lampu dan pawang laut (nakhoda) memperhatikan kondisi lingkungan (cahaya lampu, arus, angin dan kedatangan ikan).

Proses hauling dimulai dengan mematikan lampu. Lampu dimatikan satu persatu dimulai dari lampu tiang atas, lampu pagar, dan lampu bagian belakang. Nakhoda kemudian mengamati sedikit banyaknya ikan yang berkumpul di sekitar lampu yang masih menyala. Jika ikan dilihat terlalu sedikit maka jaring tidak akan diturunkan dan semua lampu akan dinyalakan kembali, namun jika ikan terlihat banyak maka jaring dari bagian belakang bagan akan diturunkan. Penurunan jaring dimulai dengan menurunkan pemberat dan kemudian diikuti penurunan jaring.

Lampu yang masih menyala akan kembali dimatikan satu persatu setelah jaring berada diperairan dan hanya lampu berwarna hijau yang akan tetap dihidupkan, tujuannya agar ikan dapat terkonsentrasi dipermukaan air dan ditengah-tengah jaring. Proses selanjutnya adalah penarikan jaring yang dilakukan dengan memutar roller/tuas penarik secara perlahanlahan, hal ini dilakukan agar ikan tidak terkejut dan meloloskan diri dari jaring. Putaran roller/tuas penarik semakin dipercepat pada saat jaring mendekati permukaan air, hal ini bertujuan untuk menghindari ikan yang lolos karena ikan mengetahui ada benda asing yang bergerak mendekatinya. Pinggir jaring dikait dengan galah bambu setelah sisi pinggir jaring terlihat dipermukaan dan kemudian diambil secara manual untuk memposisikan seluruh jaring hanya berada di bagian sisi dalam perahu.

Hasil tangkapan yang didapat selanjutnya diambil dengan serok dan dimasukkan ke dalam raga (keranjang). Semua lampu kemudian kembali dihidupkan untuk melakukan setting alat tangkap yang ke dua. Proses Setting biasanya dilakukan sebanyak 2 sampai 3 kali dalam satu malam penangkapan. Jika kondisi fishing ground dinilai tidak menguntungkan menurut pawang, maka bagan utama akan ditarik menuju fishing ground yang lainnya.

\section{Identifikasi alat bantu lampu}

Lampu merupakan alat bantu utama pada perikanan bagan apung sebagai penarik perhatian ikan. Ikan-ikan yang tertarik dengan cahaya lampu akan mendekat dan berenang disekitar cahaya sehingga dapat dilakukan operasi penangkapan. Jenis lampu yang digunakan oleh nelayan bagan apung di daerah Perairan Krueng Raya adalah lampu neon (fluorenscen) dan lampu mercury dengan kapasitas yang berbeda. Penggunaan lampu neon dan lampu mercury sebagai alat bantu pada bagan apung menurut pemaparan Sudirman et al. (2013) dapat menghasilkan tangkapan yang 
lebih banyak jika dibandingkan dengan penggunaan lampu pijar. Lampu neon yang digunakan pada bagan apung di Perairan Krueng Raya terdiri dari 2 jenis, yakni 10 buah yang berkapasitas 36 watt dan 65 buah yang erkapasitas 40 watt, sedangkan lampu mercury memiliki kapasitas 400 watt. Jenis lampu pada bagan apung di Perairan Krueng Raya dapat dilihat pada Gambar 2 berikut:
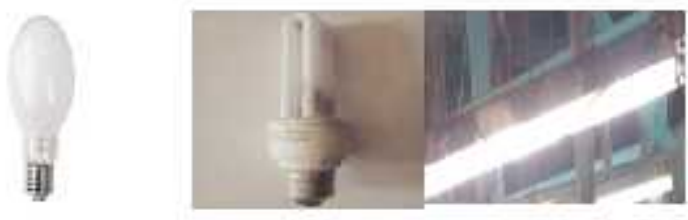

a.

\section{[?.}

Gambar 2. Jenis lampu pada bagan apung Krueng Raya (a) lampu mercury; (b) lampu neon

Lampu neon yang digunakan pada bagan apung di Perairan Krueng Raya berwarna putih dan berjumlah 77 buah yang tersebar pada tiang bagian atas, pagar, bagian bawah bagan dan 1 buah lampu berwarna hijau dicelupkan kedalam air. Ikan teri dan cumi-cumi sebagai target utama tangkapan bagan apung menurut Gustaman et al.(2012)akan lebih efektif akan lebih efektif jika menggunakan lampu berwarna putih dan kuning jika dibandingkan dengan lampu yang berwarna lainnya. Penggunaan lampu celup bawah air menurut Sukandar dan Fuad (2015) sangat efektif digunakan untuk meningkatkan hasil tangkapan. Posisi penempatan lampu yang berada di atas permukaan air menurut Ermawati (2012) juga akan sedikit kurang efektif jika dibandingkan dengan penempatan lampu yang berada di dalam air. Lampu mercury yang digunakan berjumlah 2-4 buah yang terletak dibagian bawah bangunan bagan apung. Jenis dan tata letak lampu pada bagan apung di Perairan Krueng Raya dapat dilihat pada gambar berikut:

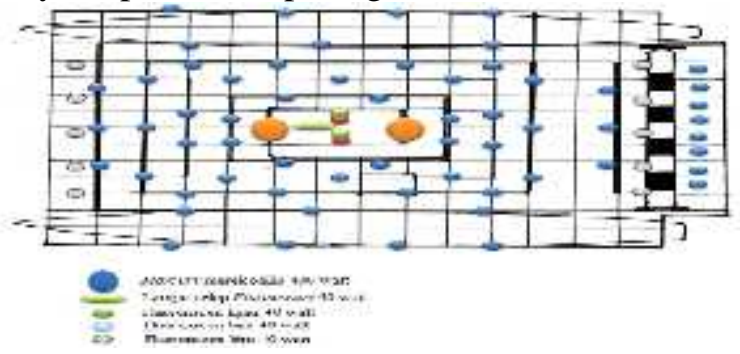

Gambar 3. Tata letak lampu pada bagan apung di Perairan Krueng Raya
Lampu pada bagan apung di Perairan Krueng Raya juga dihidupkan sejak hari mulai gelap dan hanya dimatikan saat akan dilakukan hauling. Lampu pada bagan apung di Perairan Krueng Raya dipadamkan satu persatu dimulai dari lampu tiang atas, lampu pagar, dan lampu bagian belakang bawah. Penurunan jaring dimulai dengan menurunkan pemberat dan kemudian diikuti penurunan jaring. Lampu yang masih menyala akan kembali dimatikan satu persatu setelah jaring berada diperairan dan hanya lampu berwarna hijau yang akan tetap dihidupkan. Tahapan pemadaman lampu pada bagan apung di Perairan Krueng Raya dapat dilihat pada gambar berikut:

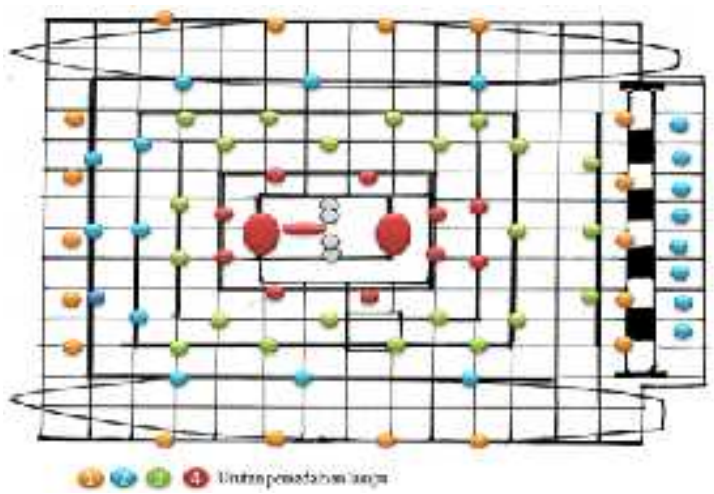

Gambar 4. Tahapan pemadaman lampu pada bagan apung di Perairan Krueng Raya

\section{Identifikasi alat bantu genset}

Genset merupakan alat yang berfungsi untuk menghasilkan daya listrik. Genset pada bagan apung berfungsi sebagai sumber listrik untuk menghidupkan lampu dan kebutuhan listrik lainnya. Genset menurut pemaparan Suyanto (2015) merupakan alat yang dapat mengubah energi mekanik menjadi energi listrik, dimana genset akan mengubah energi pada bahan bakar menjadi energi gerak oleh mesin dan kemudian diubah menjadi energi listrik.

Jenis genset yang digunakan pada bagan apung di Perairan Krueng Raya adalah Yanmar 5000 watt dengan kebutuhan bahan bakar untuk satu malam melaut kurang lebih sebanyak 15 liter. Perawatan genset dilakukan dengan mengganti oli setiap 1 bulan sekali. Berikut gambar genset dan penempatannya pada bagan apung: 


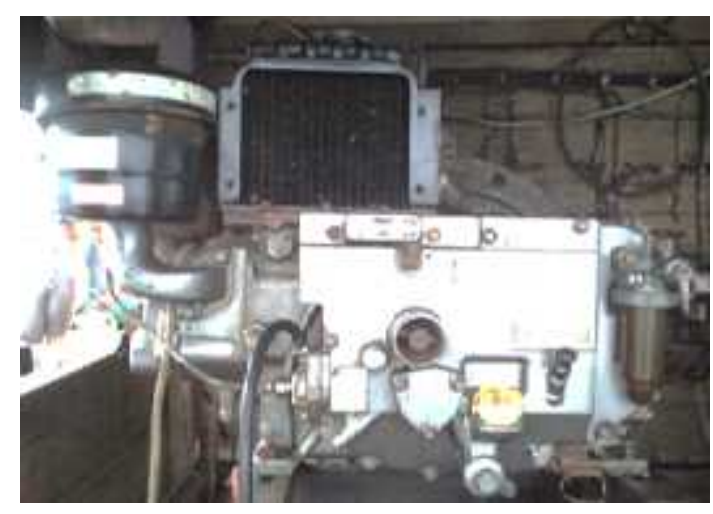

Gambar 5. Jenis genset pada bagan apung Krueng Raya

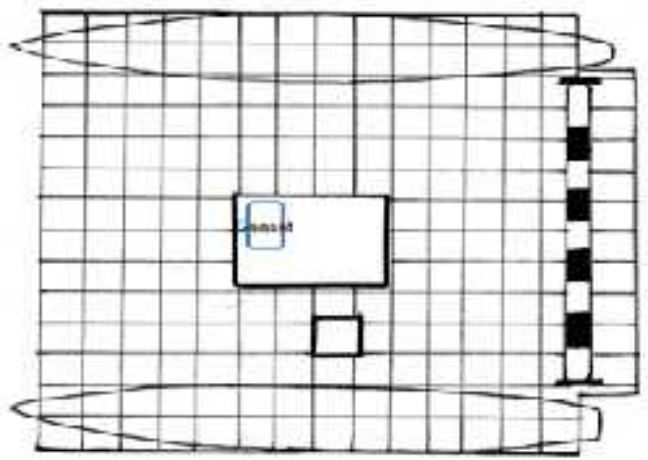

Gambar 6. Letak genset pada bagan apung Krueng Raya

\section{Identifikasi alat bantu roller}

Roller yang digunakan pada bagan apung di Perairan Krueng Raya terbuat dari kayu bayur (Pterospermum javanicum) dan kayu kelapa (Cocos sp.), dengan panjang $4 \mathrm{~m}$, diameter 10,82 $\mathrm{cm}$ dan berada dibagian belakang bagan apung. Kayu bayur merupakan jenis kayu yang banyak ditemukan di daerah maluku yang memiliki berat jenis sebesar 0,46, umur selama 34 tahun dengan diameter maksimal mencapai $44 \mathrm{~cm}$ (Basri, 2005). Diameter roller pada bagan apung menurut Mohammad et al.(1999) memiliki hubungan terhadap kecepatan tarikan tali jaring, yakni semakin besar diameter roller,maka waktu penarikan tali jaring akan semakin singkat hal ini dikarenakan semakin sedikit jumlah putaran yang diperlukan dalam penarikan tali tersebut. Perawatan roller dilakukan dengan melapisi kayu dengan cat minyak dan penggantian kayu dilakukan tiap 5 tahun sekali. Posisi katrol pada bagan apung dapat dilihat pada gambar berikut:

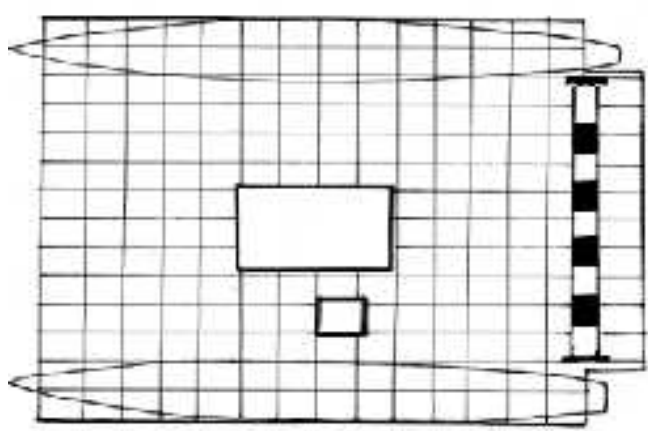

Gambar 7. Posisi roller pada bagan apung Krueng Raya

\section{SIMPULAN}

lampu yang digunakan pada tiap bagan apung di Perairan Krueng Rayasebagian besar berjumlah 77 buah yang terdiri dari terdiri dari 2 buah lampu mercury 400 watt, 10 buah lampu neon 36 watt dan 65 buah lampu neon 40 watt. Genset digunakan pada bagan apung di Perairan Krueng Raya memiliki kapasitas 5000 watt. Jenis kayu yang digunakan pada roller bagan apung Krueng Raya adalah kayu bayur (Pterospermum javanicum) dan kayu kelapa (Cocos sp.).

\section{DAFTAR PUSTAKA}

Basri, E. 2005. Mutu Kayu Mangium dalam Beberapa Metode Pengeringan. Jurnal Penelitian Hasil Hutan, 23 (2): 119 -129.

[BPS] Badan Pusat Statistik Aceh. 2015. Buku Statistik Perencanaan Pembangunan Daerah Provinsi Aceh: Banda Aceh.

Ermawati, N. I. 2012. Pengaruh perbedaan posisi penempatan lampu tabung terhadap hasil tangkapan. [Skripsi] Institut Pertanian Bogor: Bogor

Gustaman, G., Fauziyah., Isnaini. 2012. Efektifitas Perbedaan Warna Cahaya Lampu Terhadap Hasil Tangkapan Bagan Tancap di Perairan Sungsang Sumatera Selatan. Jurnal Maspari, 4(1): 92-102.

Mohammad, I., W. Mawardi., Darmawan. 1999. Pengaruh Kecepatan Penarikan Jaring (Hauling) Terhadap Hasil Tangkapan Bagan Apung di Pelabuhan ratu. Bulletin PSP, 7(1): 45-54. 
Puspito, G. 2012. Pengaruh Pemusatan Cahaya Terhadap Efektivitas Bagan. Jurnal Saintek Perikanan, 7(2): 5-9.

Sudirman., Najamuddin., M. Palo. 2013. Efektivitas Penggunaan Berbagai Jenis Lampu Listrik untuk Menarik Perhatian Ikan Pelagis Kecil pada Bagan Tancap. Jurnal Penelitian Perikanan Indonesia, 19 (3): 157-165.

Sudirman dan A. Mallawa. 2012. Teknik Penangkapan Ikan. Edisi revisi. Rineka Cipta: Jakarta.
Sukandar dan Fuad, 2015. Pengoperasian Lampu Celup Bawah Air pada Bagan Tancap di Perairan Lekok. Journal of Innovation and Applied Technology,1(2): 101-105.

Suyanto, M. 2015. Pengukuran Daya Keluaran Inverter pada Pembangkit Listrik Mikrohidro dengan Alternator DC. Jurnal Teknologi, 10(1): 42-49. 